\title{
One-Step High-Temperature-Synthesized Single-Atom Platinum Catalyst for Efficient Selective Hydrogenation
}

\author{
Qingyuan Bi, ${ }^{1}$ Xiaotao Yuan, ${ }^{2}$ Yue Lu, ${ }^{3}$ Dong Wang, ${ }^{1}$ Jian Huang, ${ }^{1}$ Rui Si $\mathbb{D}^{,},{ }^{4}$ Manling Sui $\left(\mathbb{D},{ }^{3}\right.$ \\ and Fuqiang Huang $\mathbb{D i D}^{1,2}$ \\ ${ }^{1}$ State Key Laboratory of High Performance Ceramics and Superfine Microstructure, Shanghai Institute of Ceramics, \\ Chinese Academy of Sciences, Shanghai 200050, China \\ ${ }^{2}$ State Key Laboratory of Rare Earth Materials Chemistry and Applications, College of Chemistry and Molecular Engineering, \\ Peking University, Beijing 100871, China \\ ${ }^{3}$ Institute of Microstructure and Properties of Advanced Materials, Beijing University of Technology, Beijing 100124, China \\ ${ }^{4}$ Shanghai Synchrotron Radiation Facility, Shanghai Institute of Applied Physics, Chinese Academy of Sciences, \\ Shanghai 201800, China
}

Correspondence should be addressed to Rui Si; sirui@sinap.ac.cn, Manling Sui; mlsui@bjut.edu.cn, and Fuqiang Huang; huangfq@mail.sic.ac.cn

Received 20 December 2019; Accepted 22 March 2020; Published 29 April 2020

Copyright (c) 2020 Qingyuan Bi et al. Exclusive Licensee Science and Technology Review Publishing House. Distributed under a Creative Commons Attribution License (CC BY 4.0).

\begin{abstract}
Although single-atom catalysts significantly improve the atom utilization efficiency, the multistep preparation procedures are complicated and difficult to control. Herein, we demonstrate that one-step in situ synthesis of the single-atom Pt anchored in single-crystal $\mathrm{MoC}\left(\mathrm{Pt}_{1} / \mathrm{MoC}\right)$ by using facile and controllable arc-discharge strategy under extreme conditions. The high temperature (up to $4000^{\circ} \mathrm{C}$ ) provides the sufficient energy for atom dispersion and overall stability by forming thermodynamically favourable metal-support interactions. The high-temperature-stabilized $\mathrm{Pt}_{1} / \mathrm{MoC}$ exhibits outstanding performance and excellent thermal stability as durable catalyst for selective quinoline hydrogenation. The initial turnover frequency of $3710 \mathrm{~h}^{-1}$ is greater than those of previously reported samples by an order of magnitude under $2 \mathrm{MPa}_{2}$ at $100^{\circ} \mathrm{C}$. The catalyst also shows broad scope activity toward hydrogenation containing unsaturated groups of $\mathrm{C}=\mathrm{C}, \mathrm{C}=\mathrm{N}$, and $\mathrm{C}=\mathrm{O}$. The facile, one-step, and fast arc-discharge method provides an effective avenue for single-atom catalyst fabrication that is conventionally challenging.
\end{abstract}

\section{Introduction}

Single-atom catalysts (SACs) with unique electronic/geometric structures exhibit more effective atom utilization and can act as a promising bridge between homogeneous and heterogeneous catalysis [1-14]. The stability of SACs is a critical issue for their practical applications [15-17]. It was reported that the presence of subnanometer clusters in SACs can affect the overall thermal stability [18-23]. Tremendous efforts are made to improve the thermal stability by enhancing the metal-support interactions [1-17]. Currently, most SACs are prepared by the confinement and coordination of active metal atoms to the defective substrates via adsorption $[24,25]$, coprecipitation $[1,26]$, atomic layer deposition [27], galvanic replacement [28-30], and ionic exchange $[11,31]$ under mild conditions. However, the multistep procedures and complicated processes generally breed the inevitable difficulty in precise controlling of the atomic dispersion. It can also lead to the waste of resources and the generation of environmentally unfriendly by-products. Most recently, high-temperature-assisted routes (e.g., pyrolysis, fusion, and high-temperature shockwave) have been successfully utilized to synthesize the SACs and attract ever-increasing attention [32-36]. It was widely 
accepted that high temperature can significantly facilitate the formation of metal-support bonds or enhance the metalatom-support interactions and thus result in excellent thermal stability [32-36]. Nevertheless, high-temperature $\left(>3000^{\circ} \mathrm{C}\right)$ synthesis of SACs remains a challenge.

Herein, we present the use of high-temperature arc discharge to directly synthesize and stabilize platinum (Pt) single atoms in molybdenum carbide (MoC) substrate at ultrahigh temperatures (up to $4000^{\circ} \mathrm{C}$ ). Compared to the traditional metal oxides, MoC shows excellent electrical conductivity which is beneficial for the electron transfer between active Pt sites and substrate and the formation of unique electronic/geometric structures. In contrast to the previously reported results [37], our MoC substrate is a typical single crystal with a small particle size. The hightemperature arc-discharge process provides sufficient activation energy for the formation of MoC substrate and strong $\mathrm{Pt}-\mathrm{MoC}$ interactions, which is critical to achieve the $\mathrm{Pt}$ single-atom dispersion for overall stability in practical applications. This facile one-step synthesis strategy under extreme conditions can avoid the uncontrollable factors generally existing in conventional multistep procedures and largely shorten the preparation time to only tens of minutes. The high-temperature-stabilized single-atom Pt catalyst $\left(\mathrm{Pt}_{1} / \mathrm{MoC}\right)$ shows outstanding performance and excellent stability for the selective hydrogenation reaction, which is a key process for the synthesis of drugs, dyes, agrochemicals, and many biologically active intermediates [38-44]. Importantly, $\mathrm{Pt}_{1} / \mathrm{MoC}$ exhibits a turnover frequency (TOF) greater than those of existing catalysts by an order of magnitude in quinoline hydrogenation under mild conditions. Furthermore, the versatile $\mathrm{Pt}$ SAC shows a broad scope activity toward selective hydrogenation containing unsaturated groups of $\mathrm{C}=\mathrm{C}, \mathrm{C}=\mathrm{N}$, and $\mathrm{C}=\mathrm{O}$.

\section{Results and Discussion}

MoC and Pt/MoC were synthesized via the facile one-step high-temperature arc-discharge strategy (Figures 1(a) and S1) $[45,46]$. Note that the arc discharge process only takes tens of minutes (Figure S2), which can largely shorten the overall preparation time. As depicted in Figures 1(b) and 1(c), the pure single-crystal MoC with a considerable specific surface area (Figure S3 and Table S1) was readily obtained. The Pt nanoparticles (NPs) and even Pt single atom in MoC were also in situ formed, as shown in Figures 1(d)-1(g). X-ray diffraction (XRD) patterns presented in Figure S4 clearly show the exclusive presence of $\mathrm{MoC}$ phase with the face-centered-cubic $\alpha$-MoC structure [37]. The absence of any Pt-containing phases indicates the high dispersion of Pt species. High-resolution transmission electron microscopy (HRTEM) data of $1 \%$ $\mathrm{Pt} / \mathrm{MoC}$ (Figure S5) demonstrates the formation of small Pt NPs with a diameter of $2.2 \pm 0.2 \mathrm{~nm}$. Clearly, the particle size decreases with the $\mathrm{Pt}$ loading decreasing. No appearance of $\mathrm{Pt} \mathrm{NPs}$ was observed in $\mathrm{Pt}_{1} / \mathrm{MoC}$. Highangle annular dark field- (HAADF-) scanning transmission electron microscopy (STEM) combined with energydispersive spectroscopy (EDS) reveals the formation of

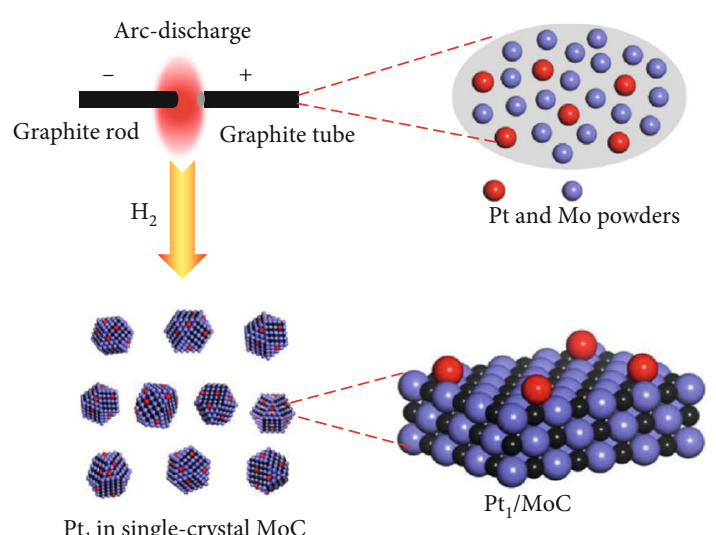

(a)
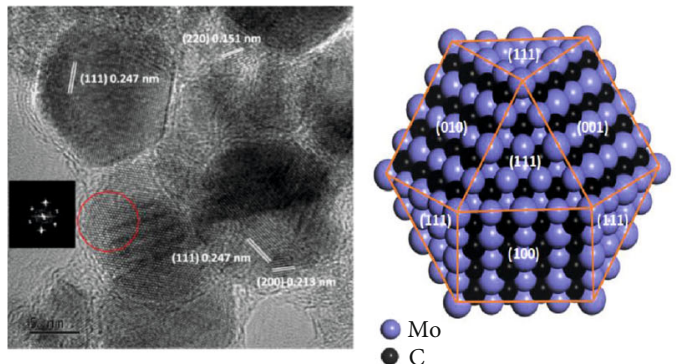

(b)

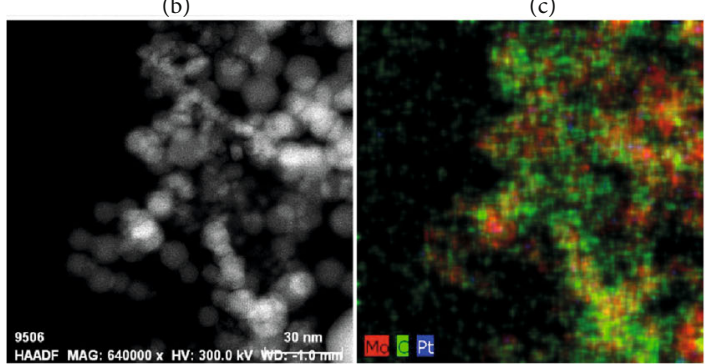

(d)

(e)
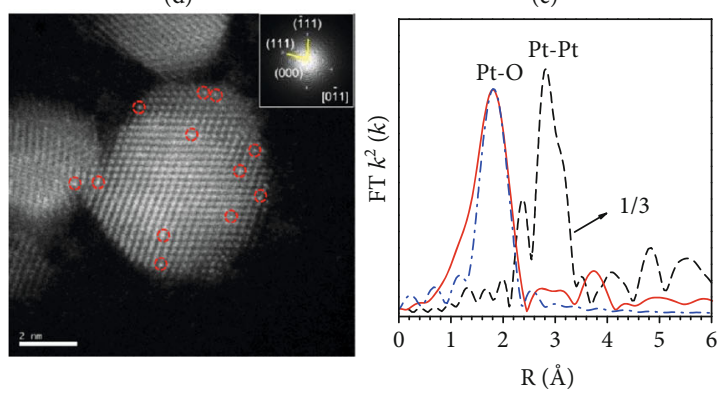

- - Pt foil

- Ptl/MoC

-..- Pt fitting

(f)

(g)

FIgURE 1: (a) One-step high-temperature synthesis of $\mathrm{Pt}_{1} / \mathrm{MoC}$ catalyst via arc-discharge route. (b) HRTEM image and (c) crystal structure of single-crystal MoC. The crystal plane parameters and selected fast Fourier transform (FFT) results are demonstrated in (b). (d) HAADF-STEM image; (e) EDS Mo, C, and Pt mappings; and (f) aberration-corrected STEM-HAADF image of $\mathrm{Pt}_{1} / \mathrm{MoC}$. The presence of atomically dispersed $\mathrm{Pt}$ in (f) is highlighted by the red circles. Inset in (f) is the FFT data of $\mathrm{Pt}_{1} / \mathrm{MoC}$. (g) FT-EXAFS spectra of $\mathrm{Pt}_{1} / \mathrm{MoC}$ and bulk $\mathrm{Pt}$ foil at the $\mathrm{Pt} L_{3}$-edge, showing the surrounding atoms adjacent to Pt atoms. 


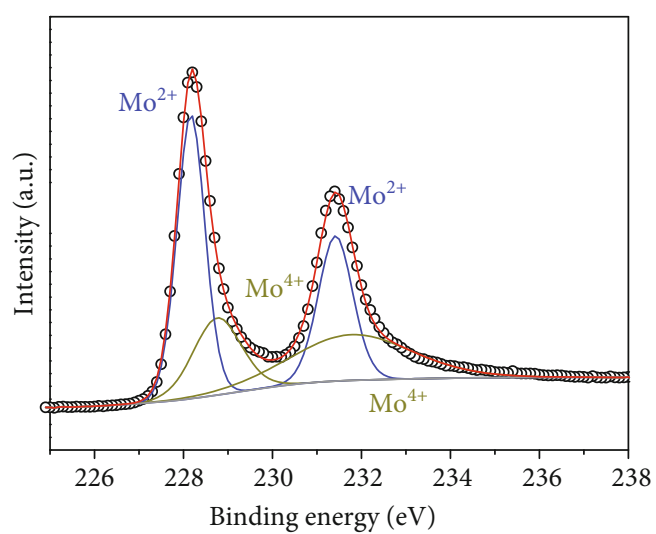

(a)

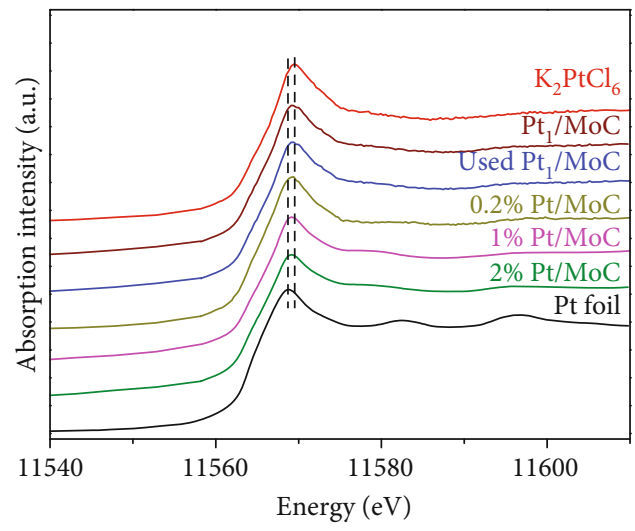

(c)

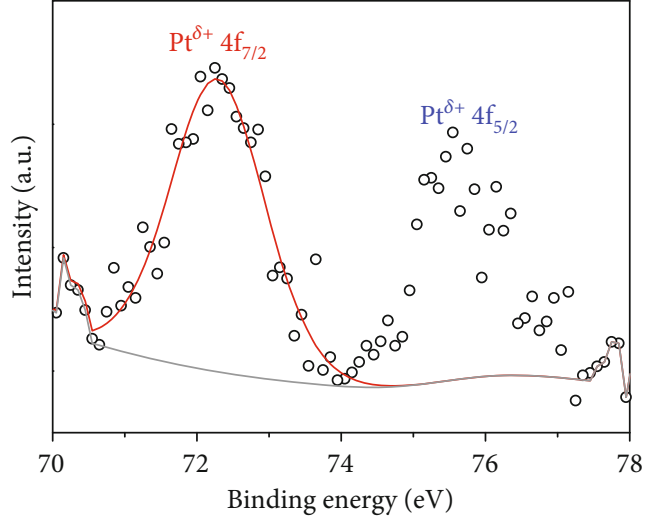

(b)

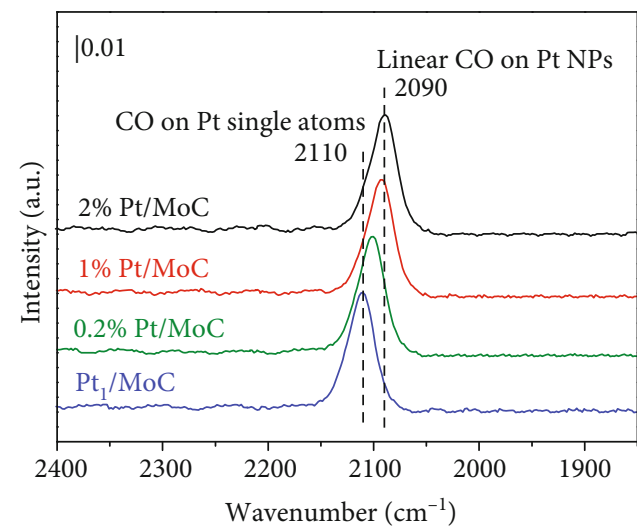

(d)

Figure 2: XPS (a) Mo 3d and (b) Pt $4 \mathrm{f}$ of $\mathrm{Pt}_{1} / \mathrm{MoC}$. (c) Pt $L_{3}$-edge XANES and (d) in situ DRIFTS of CO adsorbed on Pt-based samples.

atomic $\mathrm{Pt}$ in $\mathrm{Pt}_{1} / \mathrm{MoC}$ (Figures 1(d), 1(e), and S6). Aberration-corrected STEM-HAADF images exhibit direct observation of the Pt single atoms (Figures 1(f) and S7). Pt dopant gave no change on the single crystal nature of matrix (inset in Figure 1(f)), and the isolated Pt atoms were tenaciously anchored in $\mathrm{MoC}$ substrate. To further verify the atomically dispersed $\mathrm{Pt}$ in $\mathrm{Pt}_{1} / \mathrm{MoC}$, Fourier transformextended X-ray absorption fine structure (FT-EXAFS) spectra were performed (Figures $1(\mathrm{~g}), \mathrm{S} 8$, and S9 and Table S2). Only one notable peak at ca. $2 \AA$ from the Pt-O contribution is observed, and no signal in the region 2.5 to $3 \AA$ from the Pt-Pt contribution appears, indicative of the sole presence of single-atom $\mathrm{Pt}$ in $\mathrm{Pt}_{1} / \mathrm{MoC}$ (Table S2) $[1,37]$.

X-ray photoelectron spectroscopy (XPS) data of Mo 3d for $\mathrm{Pt}_{1} / \mathrm{MoC}$ catalyst demonstrates that Mo exists in $\mathrm{Mo}^{4+}$ and $\mathrm{Mo}^{2+}$ states (Figure 2(a)). Pt 4f XPS depicted in Figures 2(b) and S10 show that the atomically dispersed Pt is in the $\mathrm{Pt}^{\delta+}$ state, indicative of the unique electron structure of $\mathrm{Pt}$ single atoms in $\mathrm{Pt}_{1} / \mathrm{MoC}[1,37]$. Normalized X-ray absorption near-edge structure (XANES) spectra at the Pt $L$ -edge of $\mathrm{Pt} / \mathrm{MoC}$ show a visible blue-shift from $\mathrm{Pt}$ foil to $\mathrm{Pt}_{1} / \mathrm{MoC}$ (Figure 2(c)), indicating that the Pt single atoms in $\mathrm{Pt}_{1} / \mathrm{MoC}$ possess positive charges in ambient atmosphere. In situ diffuse reflectance infrared Fourier transform spectroscopy (DRIFTS) was conducted to detect the CO chemical adsorption on Pt/MoC (Figure 2(d)). The band at $2090 \mathrm{~cm}^{-1}$ is ascribed to CO linearly adsorbed on Pt NPs in $2 \% \mathrm{Pt} / \mathrm{MoC}$. As Pt size decreases, significant blueshift occurs for $\mathrm{CO}$ adsorption (2093 and $2101 \mathrm{~cm}^{-1}$ for $1 \% \mathrm{Pt} / \mathrm{MoC}$ and $0.2 \% \mathrm{Pt} / \mathrm{MoC}$, respectively). The band at $2110 \mathrm{~cm}^{-1}$ is assigned to CO adsorbed on atomically dispersed Pt species, further confirming the fine isolation of $\mathrm{Pt}$ atoms in $\mathrm{Pt}_{1} / \mathrm{MoC}$ catalyst $[1-3,37]$.

Quinoline hydrogenation was selected as a model reaction to evaluate the catalytic activity of $\mathrm{Pt} / \mathrm{MoC}$. All the $\mathrm{Pt} / \mathrm{MoC}$ catalysts were found to be highly efficient for selective quinoline hydrogenation under $2 \mathrm{MPa}_{2}$ at $100^{\circ} \mathrm{C}$, as the selectivity of $>99 \%$ to 1,2,3,4-tetrahydroquinoline listed in Table 1 . No trace of frequently generated by-products like 5,6,7,8-tetrahydroquinoline or decahydroquinoline was observed. As Pt size decreases, the average TOF significantly increases from $393 \mathrm{~h}^{-1}$ for $2 \% \mathrm{Pt} / \mathrm{MoC}$ to $766 \mathrm{~h}^{-1}$ for $1 \%$ $\mathrm{Pt} / \mathrm{MoC}$ to $1921 \mathrm{~h}^{-1}$ for $0.2 \% \mathrm{Pt} / \mathrm{MoC}$ (Table 1, entries 1-4). Remarkably, $\mathrm{Pt}_{1} / \mathrm{MoC}$ shows outstanding average TOF of $3380 \mathrm{~h}^{-1}$ (initial TOF of $3710 \mathrm{~h}^{-1}$ ) and near full conversion $(>99 \%)$ for quinoline transformation (entries 5 and 6 ). Noteworthy, the exceptional TOF is greater than those of previously reported catalysts by an order of magnitude for quinoline hydrogenation under mild conditions (Table S3) [42-44, 47-49]. $\mathrm{Pt}_{1} / \mathrm{MoC}$ can also achieve selective reaction at low temperature of $60^{\circ} \mathrm{C}$ (entry 7) or under low $\mathrm{H}_{2}$ pressure of $1 \mathrm{MPa}$ (entry 8). For the Pt catalysts with 
TABLE 1: Study of various solid catalysts for the selective hydrogenation of quinoline ${ }^{\mathrm{a}}$.

\begin{tabular}{|c|c|c|c|c|c|}
\hline Entry & Catalyst & Conv. (\%) & Sel. (\%) & TOF $\left(h^{-1}\right)^{b}$ & TOF $\left(h^{-1}\right)^{c}$ \\
\hline $1^{\mathrm{d}}$ & $2 \% \mathrm{Pt} / \mathrm{MoC}$ & $>99$ & $>99$ & 393 & 2038 \\
\hline 2 & $1 \% \mathrm{Pt} / \mathrm{MoC}$ & 95.8 & $>99$ & 766 & 2465 \\
\hline $3^{\mathrm{e}}$ & $0.5 \% \mathrm{Pt} / \mathrm{MoC}$ & 76.6 & $>99$ & 1225 & 2792 \\
\hline $4^{\mathrm{f}}$ & $0.2 \% \mathrm{Pt} / \mathrm{MoC}$ & 96.3 & $>99$ & 1921 & 3143 \\
\hline $5^{\mathrm{g}}$ & $\mathrm{Pt}_{1} / \mathrm{MoC}$ & 84.5 & $>99$ & 3380 & 3710 \\
\hline $6^{\mathrm{g}, \mathrm{h}}$ & $\mathrm{Pt}_{1} / \mathrm{MoC}$ & $>99$ & $>99$ & 1975 & 3687 \\
\hline $7^{\mathrm{h}, \mathrm{i}}$ & $1 \% \mathrm{Pt} / \mathrm{MoC}$ & 54.8 & $>99$ & 219 & 815 \\
\hline $8^{j}$ & $1 \% \mathrm{Pt} / \mathrm{MoC}$ & 61.7 & $>99$ & 494 & 1630 \\
\hline 9 & $1 \% \mathrm{Pt} / \mathrm{NbC}$ & 75.9 & 95.6 & 582 & - \\
\hline 10 & $1 \% \mathrm{Pt} / \mathrm{WC}$ & 42.6 & 92.7 & 318 & - \\
\hline 11 & $1 \% \mathrm{Pt} / \mathrm{TiC}$ & 56.8 & 94.9 & 433 & - \\
\hline 12 & $1 \% \mathrm{Pd} / \mathrm{MoC}$ & 81.3 & 72.5 & 470 & - \\
\hline 13 & $1 \% \mathrm{Ru} / \mathrm{MoC}$ & 85.2 & 90.6 & 623 & - \\
\hline 14 & $1 \% \mathrm{Au} / \mathrm{MoC}$ & 66.2 & 98.1 & 525 & - \\
\hline $15^{\mathrm{k}}$ & $1 \% \mathrm{Pt} / \mathrm{MoC}$ & 82.5 & $>99$ & 659 & - \\
\hline 16 & $1 \% \mathrm{Au} / \mathrm{TiO}_{2}$ & 34.7 & 75.9 & 216 & - \\
\hline
\end{tabular}

${ }^{\mathrm{a}}$ Reaction conditions: $0.025 \mathrm{~mol} \%$ metal, $2 \mathrm{~mL}$ toluene, $4.15 \mathrm{mmol}$ quinoline, $2 \mathrm{MPa} \mathrm{H}_{2}, 100^{\circ} \mathrm{C}, 5 \mathrm{~h} .{ }^{\mathrm{b}}$ Average TOF based on total metal sites. ${ }^{\mathrm{c}} \mathrm{TOF}$ based on surface Pt sites and $20 \%$ quinoline conversion. ${ }^{\mathrm{d}} 0.05 \mathrm{~mol} \% \mathrm{Pt} .{ }^{\mathrm{e}} 0.0125 \mathrm{~mol} \% \mathrm{Pt} .{ }^{\mathrm{f}} 0.01 \mathrm{~mol} \% \mathrm{Pt} .{ }^{\mathrm{g}} 0.005 \mathrm{~mol} \% \mathrm{Pt} .{ }^{\mathrm{h}} 10 \mathrm{~h} .{ }^{\mathrm{i}} 60^{\circ} \mathrm{C} .{ }^{\mathrm{j}} 1 \mathrm{MPa} \mathrm{H}_{2} .{ }^{\mathrm{k}} 1 \% \mathrm{Pt} / \mathrm{MoC}$ prepared by conventional impregnation route.

similar loading and comparable particle size (Figure S11) tested, the use of $\mathrm{MoC}$ rather than $\mathrm{NbC}, \mathrm{WC}$, and $\mathrm{TiC}$ as the most suitable support can significantly stimulate the catalysis potential of $\mathrm{Pt}$ (entries 9-11). In contrast, $\mathrm{Pd}, \mathrm{Ru}$, and $\mathrm{Au}$ with an identical size on MoC (Figure S11) show low efficiency for 1,2,3,4-tetrahydroquinoline synthesis. Only the catalysts based on $\mathrm{Pt}$ could deliver the high activity and provide the intrinsic advantages (entries 1214). Compared to the one-step high-temperature strategy, $\mathrm{Pt} / \mathrm{MoC}$ prepared by the conventional impregnation method (Figure S12) displays lower activity with the average TOF of $659 \mathrm{~h}^{-1}$ (entry 15). The commonly used $\mathrm{Au} / \mathrm{TiO}_{2}$ (Figure S13) $[40,43,50]$ exhibits very low activity with the selectivity of $75.9 \%$ (entry 16 ). Blank experiments without catalyst or use of $\mathrm{Pt}$-free MoC show no conversion further confirming the indispensable role of Pt species for the desired transformation.

To examine whether the Pt-catalyzed reaction indeed occurred on the surface of $\mathrm{Pt}_{1} / \mathrm{MoC}$, the solid was removed from the reaction system after $2 \mathrm{~h}$. Postprocessing of the filtrate under identical conditions for another $2 \mathrm{~h}$ did not increase the conversion. Furthermore, the inductively coupled plasma atomic emission spectroscopy (ICP-AES) data of the filtrate shows that the content of $\mathrm{Pt}$ or Mo in the solution is below the detection limit of $0.1 \mathrm{ppm}$, indicating the leaching is negligible during the reaction and the heterogeneous catalysis nature of $\mathrm{Pt}_{1} / \mathrm{MoC}$. The apparent activation energy $\left(E_{\mathrm{a}}\right)$ was estimated to be $32.42 \mathrm{~kJ} \mathrm{~mol}^{-1}$
(Figure S14), which is lower than those of the existing catalysts [42-44, 47-49]. $\mathrm{Pt}_{1} / \mathrm{MoC}$ can be reused at least for six runs without significant decay (Figure S15), indicative of the excellent stability for quinoline transformation. Compared to the fresh $\mathrm{Pt}_{1} / \mathrm{MoC}$, no visible changes in the morphology, single crystal nature, and surface chemical state of $\mathrm{Pt}$ species of the used $\mathrm{Pt}_{1} / \mathrm{MoC}$ were observed and no aggregation of the Pt single atoms occurred (Figures S8, S9, S10, and S16-18 and Table S2). These results demonstrate the effectiveness of $\mathrm{Pt}_{1} / \mathrm{MoC}$ catalyst for selective quinoline hydrogenation.

Moreover, $\mathrm{Pt}_{1} / \mathrm{MoC}$ was extended to the investigation of various structurally different substituted quinoline compounds, as listed in Table 2. Reactions involving a methyl group at the 2- and 4-position proceeded smoothly to produce the corresponding 1,2,3,4-tetrahydroquinolines (Table 2, entries 1 and 2). The 2-position substrate was easily hydrogenated with higher average TOF of $2102 \mathrm{~h}^{-1}$ (initial TOF of $2522 \mathrm{~h}^{-1}$ ). Low performance for 2-methyl-4-hydroxyquinoline was obtained (entry 3 ) probably due to both steric and electronic effects $[42,50,51]$. For more challenging reaction involving reducible halogen groups (e.g., -Cl and -F), $\mathrm{Pt}_{1} / \mathrm{MoC}$ shows significant activities without any dehalogenation (entries 4 and 5). Interestingly, $\mathrm{Pt}_{1} / \mathrm{MoC}$ achieves the hydrogenation of isoquinoline with high selectivity (>99\%) and moderate conversion (81.3\%) (entry 6). Furthermore, $\mathrm{Pt}_{1} / \mathrm{MoC}$ could conduct the tentative experiment of heteroaromatic indole reduction, an important process in 
TABLE 2: $\mathrm{Pt}_{1} / \mathrm{MoC}$-catalyzed selective hydrogenation of quinoline compounds ${ }^{\mathrm{a}}$.

\begin{tabular}{|c|c|c|c|c|c|c|}
\hline Entry & Substrate & Target product & Conv. (\%) & Sel. (\%) & TOF $\left(\mathrm{h}^{-1}\right)^{\mathrm{b}}$ & TOF $\left(h^{-1}\right)^{c}$ \\
\hline $1^{\mathrm{d}}$ & & & 53.1 & $>99$ & 2102 & 2522 \\
\hline 2 & & & 68.3 & $>99$ & 1352 & 1690 \\
\hline 3 & & & 45.8 & $>99$ & 906 & 1178 \\
\hline 4 & & & 86.5 & $>99$ & 1712 & 2054 \\
\hline 5 & & & 63.9 & 96.7 & 1235 & 1359 \\
\hline 6 & & & 81.3 & $>99$ & 1609 & 1908 \\
\hline 7 & & & 33.8 & 45.6 & 308 & 335 \\
\hline
\end{tabular}

${ }^{\mathrm{a}}$ Reaction conditions: $0.005 \mathrm{~mol} \% \mathrm{Pt}, 5 \mathrm{~mL}$ toluene, $3 \mathrm{mmol}$ substrate, $2 \mathrm{MPa} \mathrm{H}_{2}, 150^{\circ} \mathrm{C}, 10 \mathrm{~h}^{\mathrm{b}}{ }^{\mathrm{A}}$ Average TOF. ${ }^{\mathrm{c}} \mathrm{TOF}$ based on $20 \%$ substrate conversion. ${ }^{\mathrm{d}} 5 \mathrm{~h}$.

pharmaceutical synthesis [52], in spite of the low efficiency (entry 7).

The correlation between $\mathrm{Pt}_{1}-\mathrm{MoC}$ interactions and performance of $\mathrm{Pt}_{1} / \mathrm{MoC}$ catalyst for quinoline hydrogenation was further studied to gain insights into the reaction mechanism. Primary kinetic isotope effects (KIEs) with $\mathrm{H}_{2}$ being labeled using $\mathrm{HD}$ or $\mathrm{D}_{2}$ are summarized in Table S4 and Figure 3(a). HD and $\mathrm{D}_{2}$ show significant KIEs in the reduction process, and the latter exhibits larger value of 5.1. These results indicate that the cleavage of $\mathrm{H}-\mathrm{H}$ bond and the formation of $\mathrm{C}-\mathrm{C}$ and $\mathrm{C}-\mathrm{N}$ bonds in pyridine ring are kinetically relevant steps in quinoline hydrogenation [47]. In order to probe the potential key intermediates under the presence of $\mathrm{D}_{2}$ over surface positively charged $\mathrm{Pt}_{1} / \mathrm{MoC}$, quasi in situ Fourier transform infrared (FTIR) spectroscopy was conducted. The IR vibration of $\mathrm{O}-\mathrm{D}$ bond at $2550 \mathrm{~cm}^{-1}$ was clearly observed (Figure 3(b)), and the heterolytic dissociation of $\mathrm{H}_{2}$ was promoted by temperature, forming $\mathrm{O}-\mathrm{D}\left(\delta^{+}\right)$and $\mathrm{Pt}-\mathrm{D}\left(\delta^{-}\right)$species. Besides the intrinsic effect of the atomically dispersed $\mathrm{Pt}$ species, MoC as a conductor can also facilitate the $\mathrm{H}_{2}$ activation and dissociation [37], and the suitable Pt-MoC interactions are beneficial for these key steps. Note that the rate of $\mathrm{H}_{2}$ activation and dissociation was much faster than that of the overall process of hydrogenation $[43,47]$. Thus, the rate-determining step (RDS) can be derived from the subsequent hydrogenation with one hydrogen transfer from $\mathrm{Pt}-\mathrm{H}\left(\delta^{-}\right)$and another from $\mathrm{O}-\mathrm{H}\left(\delta^{+}\right)$to the pyridine ring.

Based on the catalytic performance, KIEs, and FTIR results, a possible reaction pathway for selective quinoline hydrogenation over $\mathrm{Pt}_{1} / \mathrm{MoC}$ was proposed (Figure 3(c)). The hydrogenation process may consist of the following four 


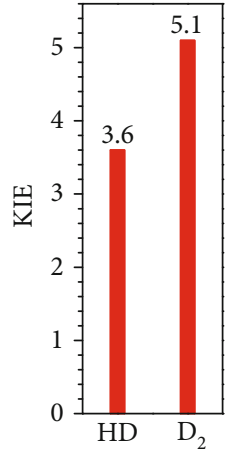

(a)

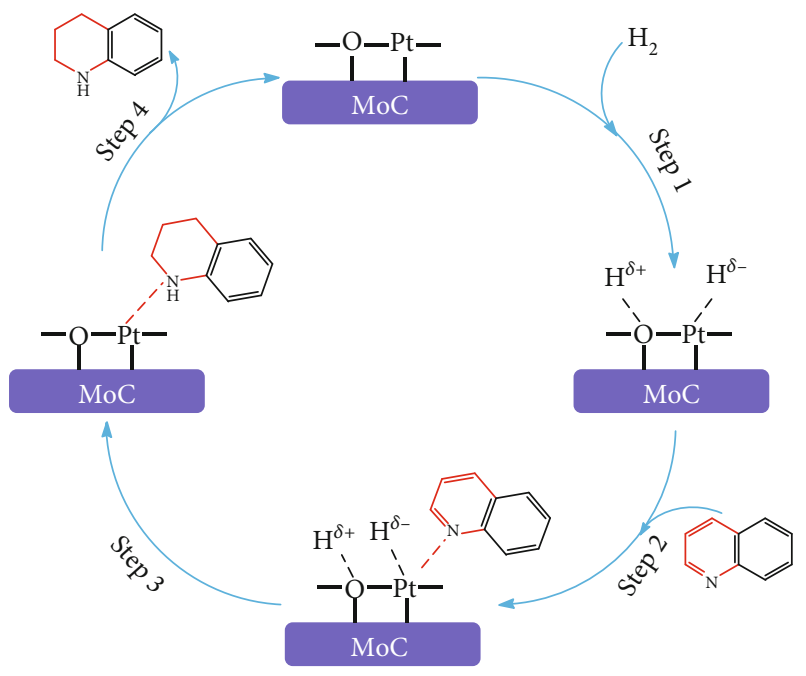

(c)
FIgURE 3: (a) KIEs of selective quinoline hydrogenation in the presence of $\mathrm{HD}$ or $\mathrm{D}_{2}$ using $\mathrm{Pt}_{1} / \mathrm{MoC}$. (b) Quasi in situ FTIR spectra of $\mathrm{Pt}_{1} / \mathrm{MoC}$ for the chemical activation of $\mathrm{D}_{2}$ at 25 and $100^{\circ} \mathrm{C}$. The $\mathrm{O}-\mathrm{D}$ vibration disappears after the introduction of styrene. (c) Possible reaction pathway for selective hydrogenation of quinoline to 1,2,3,4-tetrahydroquinoline over $\mathrm{Pt}_{1} / \mathrm{MoC}$ catalyst.

steps: (i) initial adsorption and chemical activation of $\mathrm{H}_{2}$ molecules over the positively charged Pt with heterolytic dissociation forming $\mathrm{Pt}-\mathrm{H}\left(\delta^{-}\right)$and $\mathrm{O}-\mathrm{H}\left(\delta^{+}\right)$species; (ii) chemisorption of quinoline molecules on the catalyst surface primarily through the Pt-N interaction, thus facilitating the activation of pyridine ring; (iii) generation of the adsorbed 1,2,3,4-tetrahydroquinoline via the transfer of $\mathrm{H}\left(\delta^{-}\right)$and $\mathrm{H}\left(\delta^{+}\right)$intermediates to the activated pyridine ring; and (iv) desorption of the goal product 1,2,3,4-tetrahydroquinoline from the catalyst surface. The adsorption and/or chemical activation of $\mathrm{H}_{2}$ and quinoline molecules are widely considered to be the kinetically relevant step and pyridine ring hydrogenation as the RDS [47]. Although considerable amount of energy is required for quinoline hydrogenation, the appropriate interaction of $\mathrm{Pt}-\mathrm{N}\left(\mathrm{Pt}_{1} / \mathrm{MoC}\right.$-quinoline) and the strong interactions between positively charged $\mathrm{Pt}$ atoms and MoC substrate could efficiently surpass the total reaction barriers and achieve the formation of desired 1,2,3,4-tetrahydroquinoline.

$\mathrm{Pt}_{1} / \mathrm{MoC}$ was further examined for selective hydrogenation of $\alpha, \beta$-unsaturated aldehyde involving $\mathrm{C}=\mathrm{C}$ and $\mathrm{C}=\mathrm{O}$ groups [39, 53-57]. The SAC exhibits a high efficiency with the average TOF of $1216 \mathrm{~h}^{-1}$ for crotonaldehyde hydrogenation (Table S5). This is the best performance reported for crotonaldehyde hydrogenation via heterogeneous catalysis under identical conditions and is comparable with most values gained using organic complexes [53-55]. Similar to quinoline hydrogenation, crotonaldehyde conversion using Pt NPs leads to less efficiencies (Table S5). These results again demonstrate the remarkable benefit of using single-atom Pt catalyst for selective reduction of $\alpha, \beta$-unsaturated aldehyde and further suggest the broad application prospects of $\mathrm{Pt}$ $\mathrm{SAC}$ in fine chemical synthesis.

\section{Conclusion}

A facile and controllable one-step arc-discharge strategy at ultrahigh temperature was successfully developed to synthesize single-atom $\mathrm{Pt}$ catalyst. High-temperature-stabilized $\mathrm{Pt}_{1} / \mathrm{MoC}$ with a unique electronic/geometric structure exhibits outstanding performance and excellent thermal stability for selective quinoline hydrogenation. The activity of $3710 \mathrm{~h}^{-1}$ is better than those of previously reported catalysts by an order of magnitude under similar conditions. $\mathrm{Pt}_{1} / \mathrm{MoC}$ shows broad scope activity toward hydrogenation including quinoline compounds and crotonaldehyde containing $\mathrm{C}=\mathrm{C}$, $\mathrm{C}=\mathrm{N}$, and $\mathrm{C}=\mathrm{O}$ groups. Primary kinetic isotope effects and in situ FTIR analysis show that the cleavage of $\mathrm{H}-\mathrm{H}$ bond and the formation of $\mathrm{C}-\mathrm{C}$ and $\mathrm{C}-\mathrm{N}$ bonds in pyridine ring over the positively charged $\mathrm{Pt}_{1} / \mathrm{MoC}$ are kinetically relevant steps and the latter is RDS. The possible four-step mechanism involving the heterolytic dissociation of $\mathrm{H}_{2}$ and the transfer of $\mathrm{H}\left(\delta^{-}\right)$and $\mathrm{H}\left(\delta^{+}\right)$species to the activated pyridine ring via $\mathrm{Pt}-\mathrm{N}$ bond over $\mathrm{Pt}_{1} / \mathrm{MoC}$ is proposed. We anticipate that the one-step high-temperature strategy will allow the development of broad SACs for the important yet challenging chemical transformations.

\section{Materials and Methods}

4.1. Preparation of $M o C$. The $\mathrm{MoC}$ was synthesized by a direct current arc-discharge method (Figures 1 and S1) [45, 46]. The cathode was a pure graphite rod with a diameter of $8 \mathrm{~mm}$. The anode was a graphite tube with an external diameter of $8 \mathrm{~mm}$ and an inner diameter of $6 \mathrm{~mm}$. The graphite tube was filled with Mo powders. The two electrodes were installed horizontally, and the cathode was fixed on a water-cooled copper pedestal. The arc chamber was first evacuated to $3 \mathrm{~Pa}$ and then filled by pure $\mathrm{H}_{2}$ to the pressure of $0.08 \mathrm{MPa}$. The arc was generated at a current of $80 \mathrm{~A}$, and the distance between the two electrodes was kept at about $2 \mathrm{~mm}$ by physically adjusting the cathode. The typical synthesis time was about $30 \mathrm{~min}$, and about $1 \mathrm{~cm}$ anode was consumed. After reaction, the powders generated on the top of the arc chamber were collected. 
4.2. Preparation of Pt/MoC Catalysts. In analogy to the case with $\mathrm{MoC}$, the $\mathrm{Pt} / \mathrm{MoC}$ catalysts were one-step in situ prepared by the arc-discharge method. The graphite tube, which was filled with a mixture of Pt and Mo powders, was used as anode. The mass fraction of $\mathrm{Pt}$ in the mixture depends on the mass loading of $\mathrm{Pt}$ in the final $\mathrm{Pt} / \mathrm{MoC}$ product. By controlling the $\mathrm{Pt}$ loading, the $\mathrm{Pt}_{1} / \mathrm{MoC}$ can be easily achieved.

4.3. Catalyst Characterization. XRD characterization of the samples was carried out on a German Bruker D8 Advance $\mathrm{X}$-ray diffractometer using the $\mathrm{Ni}$-filtered $\mathrm{Cu} \mathrm{K} \alpha$ radiation at $40 \mathrm{kV}$ and $40 \mathrm{~mA}$. XPS data were recorded with the Axis Ultra Photoelectron Spectrometer (Kratos Analytical Ltd.) by means of a monochromatized $\mathrm{Al} \mathrm{K} \alpha$ anode $(225 \mathrm{~W}$, $15 \mathrm{~mA}, 15 \mathrm{kV}$ ). The $\mathrm{C} 1 \mathrm{~s}$ peak at $284.8 \mathrm{eV}$ was used as the reference to calibrate the binding energies (BE). A Tecnai F20 electron microscope operating at $200 \mathrm{kV}$ equipped with an EDS unit ( $\mathrm{Si}(\mathrm{Li})$ detector) was used for the TEM investigations. The samples for electron microscopy were prepared by grinding and subsequent dispersing the powder in ethanol and applying a drop of very dilute suspension on carboncoated grids. High resolution TEM, EDS mapping, and HADDF-STEM were performed on an FEI Titan G2 (60300 ) probe-corrected TEM system with a field emission gun operated at $300 \mathrm{kV}$.

4.4. Catalytic Activity Test. The selective hydrogenations were carried out in a high-pressure stainless autoclave reactor (Parr Instrument Co., 4790, $50 \mathrm{~mL}$ ). Typically, $2 \mathrm{~mL}$ solvent (toluene or ethanol), a certain amount of substrate (quinoline or quinoline compounds or crotonaldehyde), and a known amount of catalyst were placed in the autoclave. The autoclave was sealed and flushed several times with $0.5 \mathrm{MPa} \mathrm{H}_{2}$ to remove the air in the reactor; then, $2 \mathrm{MPa} \mathrm{H}_{2}$ was charged. The stirrer $(800 \mathrm{rpm})$ was started until the desired temperature was reached. After a certain time, the autoclave was placed in cool water and the gas was carefully released. The gaseous mixture was analyzed using a gas chromatograph (GC) Agilent 7820A equipped with a TDX-01 column connected to a thermal conductivity detector. A known amount of internal standard 1,4-dioxane was added into the aqueous product in autoclave. The reaction mixture was transferred into a centrifuge tube, and the solid catalyst was separated by centrifugation. The product solution was quantitatively analyzed using a GC Agilent 7820A equipped with a HP-5 capillary column connected to a flame ionization detector. Identification of the products was performed by using a GC-MS spectrometer. Noted that the total carbon balance was $>95 \%$. For the recycling experiment, the centrifuged catalysts from parallel tests were collected and washed with distilled water several times, followed by air drying at $120^{\circ} \mathrm{C}$ for $12 \mathrm{~h}$. The KIE experiments were performed by following the same procedure as selective hydrogenations. The $\mathrm{H}_{2}$ or $\mathrm{HD}$ or $\mathrm{D}_{2}$ was, respectively, used as hydrogen source. The products were qualitatively and quantitatively analyzed using a GC and GC-MS spectrometer. The conversions of quinoline were kept below $20 \%$ for calculation of initial TOF. The unit of TOF is $\mathrm{h}^{-1}$, that is, mol target product per mol noble metal site per hour.

\section{Appendix}

Table of content.

\section{Conflicts of Interest}

The authors declare no competing financial interest.

\section{Authors' Contributions}

Q. Bi, X. Yuan, and Y. Lu contributed equally to this work. Q. $\mathrm{Bi}$ and F. Huang conceived the research. Q. Bi, X. Yuan, D. Wang, and J. Huang contributed to the catalyst preparation, experimental measurements, and data analysis. Y. Lu and M. Sui performed the aberration-corrected STEM-HAADF. R. $S i$ provided experimental guidance for the FT-EXAFS and XANES spectra. Q. Bi and X. Yuan wrote the paper. All authors reviewed and commented on the manuscript before publication.

\section{Acknowledgments}

This work was financially supported by the National Key Research and Development Program of China (2016YFB0901600), the NSF of China (21872166), and the Key Research Program of Chinese Academy of Sciences (QYZDJ-SSW-JSC013 and KGZD-EW-T06).

\section{Supplementary Materials}

Figure S1: photograph of high-temperature arc-discharge facility. The facility consists of four main parts of vacuum system, control system, water-cooled system, and arcdischarge chamber. Figure S2: summary of the results of single-atom catalyst synthesis temperatures and time by one-step high-temperature arc-discharge strategy and other techniques (wet chemical, atomic layer deposition, furnace annealing, and shockwave) in the literature. Figure S3: N2 adsorption-desorption isotherms of MoC sample. Table S1: properties of $\mathrm{MoC}$ and $\mathrm{Pt} / \mathrm{MoC}$ catalysts. Figure S4: XRD patterns of $\mathrm{MoC}$ and $\mathrm{Pt} / \mathrm{MoC}$ samples. The absence of the dominant $\mathrm{Pt}(111)$ crystal phase at 2 theta of $39.4 \mathrm{o}$ even with the loading content of $\mathrm{Pt}$ as high as $2 \mathrm{wt} \%$ indicates the high dispersion of the Pt species. Figure S5: HRTEM images of $1 \%$ $\mathrm{Pt} / \mathrm{MoC}$ catalyst. Figure S6: (a) TEM image and (b) HAADFSTEM-EDS elemental mappings of $\mathrm{Mo}, \mathrm{C}$, and $\mathrm{Pt}$ of Pt1/MoC catalyst. Figure S7: aberration-corrected STEMHAADF image of Pt1/MoC catalyst. Atomically dispersed $\mathrm{Pt}$ atoms are highlighted by the red circles. Figure S8: EXAFS Fourier transform moduli at $\mathrm{Pt} L_{3}$-absorption edge of (a) $0.2 \% \mathrm{Pt} / \mathrm{MoC}$, (b) $1 \% \mathrm{Pt} / \mathrm{MoC}$, (c) $2 \% \mathrm{Pt} / \mathrm{MoC}$, and (d) used $\mathrm{Pt} 1 / \mathrm{MoC}$ samples. Table S2: EXAFS parameters of $\mathrm{Pt} / \mathrm{MoC}$ samples. Figure S9: data and imaginary portion of the FTEXAFS spectra of (a) Pt1/MoC, (b) used Pt1/MoC, (c) $0.2 \%$ $\mathrm{Pt} / \mathrm{MoC}$, (d) $1 \% \mathrm{Pt} / \mathrm{MoC}$, and (e) $2 \% \mathrm{Pt} / \mathrm{MoC}$ samples. Figure S10: Pt 4f XPS data of (a) $0.2 \% \mathrm{Pt} / \mathrm{MoC}$, (b) $0.5 \% \mathrm{Pt} / \mathrm{MoC}$, (c) $1 \% \mathrm{Pt} / \mathrm{MoC}$, and (d) used Pt1/MoC. Table S3: comparison of selective hydrogenation of quinoline. Figure S11: HRTEM images of (a) $1 \% \mathrm{Pt} / \mathrm{NbC}$, (b) $1 \% \mathrm{Pt} / \mathrm{WC}$, (c) $1 \% \mathrm{Pt} / \mathrm{TiC}$, (d) $1 \% \mathrm{Pd} / \mathrm{MoC}$, (e) $1 \% \mathrm{Ru} / \mathrm{MoC}$, and (f) $1 \% \mathrm{Au} / \mathrm{MoC}$ 
catalysts. Figure S12: HRTEM images of 1\% Pt/MoC catalyst prepared using the conventional impregnation method. Figure S13: HRTEM image of $1 \% \mathrm{Au} / \mathrm{TiO}_{2}$ catalyst. Figure S14: Arrhenius plot for Pt1/MoC catalyzed selective hydrogenation of quinoline. Reaction conditions: $0.005 \mathrm{~mol} \% \mathrm{Pt}$, $2 \mathrm{~mL}$ toluene, $4.15 \mathrm{mmol}$ quinoline $(0.5 \mathrm{~mL}), 2 \mathrm{MPa} \mathrm{H}_{2}, 60-$ $100^{\circ} \mathrm{C}, 1 \mathrm{~h}$. The conversions were kept below $20 \%$ for calculation of initial TOF. Figure S15: recycling of Pt1/MoC catalyst for selective hydrogenation of quinoline. Reaction conditions for each run: $0.01 \mathrm{~mol} \% \mathrm{Pt}, 2 \mathrm{~mL}$ toluene, $4.15 \mathrm{mmol}$ quinoline $(0.5 \mathrm{~mL}), 2 \mathrm{MPa} \mathrm{H}_{2}, 100^{\circ} \mathrm{C}, 10 \mathrm{~h}$. Figure S16: (a) HAADF-STEM and (b) aberration-corrected STEMHAADF images of the used $\mathrm{Pt} 1 / \mathrm{MoC}$ catalyst. Inset in (b) is the FFT data showing the single-crystal structure of the used Pt1/MoC. Atomically dispersed Pt atoms in image (b) are highlighted by the red circles. Figure S17: (a) TEM image and (b) HAADF-STEM-EDS elemental mappings of Mo, C, and $\mathrm{Pt}$ of the used Pt1/MoC catalyst. Figure S18: aberration-corrected STEM-HAADF image of the used $\mathrm{Pt} 1 / \mathrm{MoC}$ catalyst. Atomically dispersed $\mathrm{Pt}$ atoms are highlighted by the red circles. Table S4: kinetic isotope effects of selective hydrogenation of quinoline using Pt1/MoC. Table S5: study of various solid catalysts for the selective hydrogenation of crotonaldehyde. (Supplementary Materials)

\section{References}

[1] B. Qiao, A. Wang, X. Yang et al., "Single-atom catalysis of CO

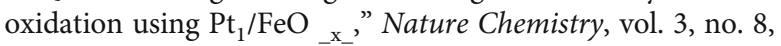
pp. 634-641, 2011.

[2] K. Ding, A. Gulec, A. M. Johnson et al., "Identification of active sites in CO oxidation and water-gas shift over supported $\mathrm{Pt}$ catalysts," Science, vol. 350, no. 6257, pp. 189-192, 2015.

[3] L. Nie, D. Mei, H. Xiong et al., "Activation of surface lattice oxygen in single-atom $\mathrm{Pt} / \mathrm{CeO}_{2}$ for low-temperature CO oxidation," Science, vol. 358, no. 6369, pp. 14191423, 2017.

[4] T. He, S. Chen, B. Ni et al., "Zirconium-porphyrin-based metal-organic framework hollow nanotubes for immobilization of noble-metal single atoms," Angewandte Chemie International Edition, vol. 57, no. 13, pp. 3493-3498, 2018.

[5] L. Liu and A. Corma, "Metal catalysts for heterogeneous catalysis: from single atoms to nanoclusters and nanoparticles," Chemical Reviews, vol. 118, no. 10, pp. 4981-5079, 2018.

[6] A. Wang, J. Li, and T. Zhang, "Heterogeneous single-atom catalysis," Nature Reviews Chemistry, vol. 2, no. 6, pp. 65-81, 2018.

[7] X. Cui, W. Li, P. Ryabchuk, K. Junge, and M. Beller, "Bridging homogeneous and heterogeneous catalysis by heterogeneous single- metal-site catalysts," Nature Catalysis, vol. 1, no. 6, pp. 385-397, 2018.

[8] P. Liu, Y. Zhao, R. Qin et al., "Photochemical route for synthesizing atomically dispersed palladium catalysts," Science, vol. 352, no. 6287, pp. 797-800, 2016.

[9] X. Zhang, Z. Sun, B. Wang et al., "C-C coupling on singleatom-based heterogeneous catalyst," Journal of the American Chemical Society, vol. 140, no. 3, pp. 954-962, 2018.

[10] J. Shan, M. Li, L. F. Allard, S. Lee, and M. Flytzani-Stephanopoulos, "Mild oxidation of methane to methanol or acetic acid on supported isolated rhodium catalysts," Nature, vol. 551, no. 7682, pp. 605-608, 2017.

[11] Z. Li, D. Wang, Y. Wu, and Y. Li, "Recent advances in the precise control of isolated single-site catalysts by chemical methods," National Science Review, vol. 5, no. 5, pp. 673689, 2018.

[12] Z. Jakub, J. Hulva, M. Meier et al., "Local structure and coordination define adsorption in a model Ir1/Fe3O4Single-Atom catalyst," Angewandte Chemie, vol. 131, no. 39, pp. 1409914106, 2019.

[13] A. S. Hoffman, L. M. Debefve, S. Zhang et al., "Beating heterogeneity of single-site catalysts: $\mathrm{MgO}$-supported iridium complexes," ACS Catalysis, vol. 8, no. 4, pp. 3489-3498, 2018.

[14] D.-L. Meng, C.-H. Chen, J.-D. Yi et al., "Migration-prevention strategy to fabricate single-atom $\mathrm{Fe}$ implanted $\mathrm{N}$-doped porous carbons for efficient oxygen reduction," Research, vol. 2019, article 1768595, pp. 1-12, 2019.

[15] Z. Zhang, Y. Zhu, H. Asakura et al., "Thermally stable single atom $\mathrm{Pt} / \mathrm{m}-\mathrm{Al}_{2} \mathrm{O}_{3}$ for selective hydrogenation and $\mathrm{CO}$ oxidation," Nature Communications, vol. 8, no. 1, p. 16100, 2017.

[16] T. W. Hansen, A. T. Delariva, S. R. Challa, and A. K. Datye, "Sintering of catalytic nanoparticles: particle migration or Ostwald ripening?," Accounts of Chemical Research, vol. 46, no. 8, pp. 1720-1730, 2013.

[17] J. Jones, H. Xiong, A. T. DeLaRiva et al., "Thermally stable single-atom platinum-on-ceria catalysts via atom trapping," Science, vol. 353, no. 6295, pp. 150-154, 2016.

[18] K. Yu, T. Xu, X. Wu et al., "In situ observation of crystalline silicon growth from SiO2at atomic scale," Research, vol. 2019, article 3289247, pp. 1-9, 2019.

[19] L. Liu, D. M. Meira, R. Arenal, P. Concepcion, A. V. Puga, and A. Corma, "Determination of the evolution of heterogeneous single metal atoms and nanoclusters under reaction conditions: which are the working catalytic sites?," ACS Catalysis, vol. 9, no. 12, pp. 10626-10639, 2019.

[20] C.-T. Kuo, Y. Lu, L. Kovarik, M. Engelhard, and A. M. Karim, "Structure sensitivity of acetylene semi-hydrogenation on $\mathrm{Pt}$ single atoms and subnanometer clusters," ACS Catalysis, vol. 9, no. 12, pp. 11030-11041, 2019.

[21] J. Resasco, F. Yang, T. Mou, B. Wang, P. Christopher, and D. E. Resasco, "Relationship between atomic scale structure and reactivity of Pt catalysts: hydrodeoxygenation ofm-Cresol over isolated Pt cations and clusters," ACS Catalysis, vol. 10, no. 1, pp. 595-603, 2020.

[22] L. DeRita, S. Dai, K. Lopez-Zepeda et al., "Catalyst architecture for stable single atom dispersion enables site-specific spectroscopic and reactivity measurements of $\mathrm{CO}$ adsorbed to $\mathrm{Pt}$ atoms, oxidized $\mathrm{Pt}$ clusters, and metallic Pt clusters on $\mathrm{TiO}_{2}$," Journal of the American Chemical Society, vol. 139, no. 40, pp. 14150-14165, 2017.

[23] J. Resasco, L. DeRita, S. Dai et al., "Uniformity is key in defining structure-function relationships for atomically dispersed metal catalysts: the case of $\mathrm{Pt} / \mathrm{CeO}_{2}$," Journal of the American Chemical Society, vol. 142, no. 1, pp. 169-184, 2020.

[24] M. Yang, S. Li, Y. Wang et al., "Catalytically active Au$\mathrm{O}(\mathrm{OH})_{\mathrm{x}}$-species stabilized by alkali ions on zeolites and mesoporous oxides," Science, vol. 346, no. 6216, pp. 1498-1501, 2014.

[25] M. Moliner, J. E. Gabay, C. E. Kliewer et al., "Reversible transformation of Pt nanoparticles into single atoms inside high- 
silica chabazite zeolite," Journal of the American Chemical Society, vol. 138, no. 48, pp. 15743-15750, 2016.

[26] J. Lin, A. Wang, B. Qiao et al., "Remarkable performance of Ir1/FeOxSingle-Atom catalyst in water gas shift reaction," Journal of the American Chemical Society, vol. 135, no. 41, pp. 15314-15317, 2013.

[27] H. Yan, H. Cheng, H. Yi et al., "Single-atom $\mathrm{Pd}_{1} /$ graphene catalyst achieved by atomic layer deposition: remarkable performance in selective hydrogenation of 1,3-butadiene," Journal of the American Chemical Society, vol. 137, no. 33, pp. 10484-10487, 2015.

[28] M. D. Marcinkowski, M. T. Darby, J. Liu et al., "Pt/Cu singleatom alloys as coke-resistant catalysts for efficient $\mathrm{C}-\mathrm{H}$ activation," Nature Chemistry, vol. 10, no. 3, pp. 325-332, 2018.

[29] L. Liu, U. Díaz, R. Arenal, G. Agostini, P. Concepción, and A. Corma, "Generation of subnanometric platinum with high stability during transformation of a $2 \mathrm{D}$ zeolite into $3 \mathrm{D}$," Nature Materials, vol. 16, no. 1, pp. 132-138, 2017.

[30] P. Yin, T. Yao, Y. Wu et al., "Single cobalt atoms with precise $\mathrm{N}$-coordination as superior oxygen reduction reaction catalysts," Angewandte Chemie International Edition, vol. 55, no. 36, pp. 10800-10805, 2016.

[31] C. Zhao, X. Dai, T. Yao et al., "Ionic exchange of metal-organic frameworks to access single nickel sites for efficient electroreduction of $\mathrm{CO}_{2}$," Journal of the American Chemical Society, vol. 139, no. 24, pp. 8078-8081, 2017.

[32] S. Wei, A. Li, J. C. Liu et al., "Direct observation of noble metal nanoparticles transforming to thermally stable single atoms," Nature Nanotechnology, vol. 13, no. 9, pp. 856-861, 2018.

[33] X. Wang, Z. Chen, X. Zhao et al., "Regulation of coordination number over single Co sites: triggering the efficient electroreduction of $\mathrm{CO}_{2}$," Angewandte Chemie International Edition, vol. 57, no. 7, pp. 1944-1948, 2018.

[34] H.-J. Qiu, Y. Ito, W. Cong et al., "Nanoporous graphene with single-atom nickel dopants: an efficient and stable catalyst for electrochemical hydrogen production," Angewandte Chemie International Edition, vol. 54, no. 47, pp. 14031-14035, 2015.

[35] X. Guo, G. Fang, G. Li et al., "Direct, nonoxidative conversion of methane to ethylene, aromatics, and hydrogen," Science, vol. 344, no. 6184, pp. 616-619, 2014.

[36] Y. Yao, Z. Huang, P. Xie et al., "High temperature shockwave stabilized single atoms," Nature Nanotechnology, vol. 14, no. 9, pp. 851-857, 2019.

[37] L. Lin, W. Zhou, R. Gao et al., "Low-temperature hydrogen production from water and methanol using $\mathrm{Pt} / \alpha-\mathrm{MoC}$ catalysts," Nature, vol. 544, no. 7648, pp. 80-83, 2017.

[38] S. Nishimura, Handbook of Heterogeneous Catalytic Hydrogenation for Organic Synthesis, Wiley-VCH, JOHN WILEY \& SONS, INC., 2001.

[39] G. Kennedy, L. R. Baker, and G. A. Somorjai, "Selective amplification of $\mathrm{C}=\mathrm{O}$ bond hydrogenation on $\mathrm{Pt} / \mathrm{TiO}_{2}$ : catalytic reaction and sum-frequency generation vibrational spectroscopy studies of crotonaldehyde hydrogenation," Angewandte Chemie International Edition, vol. 53, no. 13, pp. 3405-3408, 2014.

[40] G. Vilé, D. Albani, N. Almora-Barrios, N. López, and J. PérezRamírez, "Advances in the design of nanostructured catalysts for selective hydrogenation," ChemCatChem, vol. 8, no. 1, pp. 21-33, 2016.
[41] G. E. Dobereiner, A. Nova, N. D. Schley et al., "Iridium-catalyzed hydrogenation of $\mathrm{N}$-heterocyclic compounds under mild conditions by an outer-sphere pathway," Journal of the American Chemical Society, vol. 133, no. 19, pp. 7547-7562, 2011.

[42] X. Wang, W. Chen, L. Zhang et al., "Uncoordinated amine groups of metal-organic frameworks to anchor single Ru sites as chemoselective catalysts toward the hydrogenation of quinoline," Journal of the American Chemical Society, vol. 139, no. 28, pp. 9419-9422, 2017.

[43] D. Ren, L. He, L. Yu et al., "An unusual chemoselective hydrogenation of quinoline compounds using supported gold catalysts," Journal of the American Chemical Society, vol. 134, no. 42, pp. 17592-17598, 2012.

[44] M. Tang, J. Deng, M. Li et al., “3D-interconnected hierarchical porous $\mathrm{N}$-doped carbon supported ruthenium nanoparticles as an efficient catalyst for toluene and quinoline hydrogenation," Green Chemistry, vol. 18, no. 22, pp. 6082-6090, 2016.

[45] Q. Bi, X. Wang, F. Gu et al., "Prominent electron penetration through ultrathin graphene layer from FeNi alloy for efficient reduction of $\mathrm{CO}_{2}$ to $\mathrm{CO}$," ChemSusChem, vol. 10, no. 15, pp. 3044-3048, 2017.

[46] C. Wang, P. Zhai, Z. Zhang et al., "Nickel catalyst stabilization via graphene encapsulation for enhanced methanation reaction," Journal of Catalysis, vol. 334, no. 2, pp. 42-51, 2016.

[47] L. Bai, X. Wang, Q. Chen et al., "Explaining the size dependence in platinum-nanoparticle-catalyzed hydrogenation reactions," Angewandte Chemie International Edition, vol. 55, no. 50, pp. 15656-15661, 2016.

[48] H. Mao, J. Ma, Y. Liao, S. Zhao, and X. Liao, "Using plant tannin as natural amphiphilic stabilizer to construct an aqueousorganic biphasic system for highly active and selective hydrogenation of quinoline," Catalysis Science \& Technology, vol. 3, no. 6, pp. 1612-1617, 2013.

[49] M. Yan, T. Jin, Q. Chen et al., "Unsupported nanoporous gold catalyst for highly selective hydrogenation of quinolines," Organic Letters, vol. 15, no. 7, pp. 1484-1487, 2013.

[50] L. Tao, Q. Zhang, S. S. Li, X. Liu, Y. M. Liu, and Y. Cao, "Heterogeneous gold-catalyzed selective reductive transformation of quinolines with formic acid," Advanced Synthesis \& Catalysis, vol. 357, no. 4, pp. 753-760, 2015.

[51] H. Wei, X. Liu, A. Wang et al., " $\mathrm{FeO}_{\mathrm{x}}$-supported platinum single-atom and pseudo-single- atom catalysts for chemoselective hydrogenation of functionalized nitroarenes," Nature Communications, vol. 5, no. 1, p. 5634, 2014.

[52] D. Zhao, Z. Shi, and F. Glorius, "Indole synthesis by rhodium (III)-catalyzed hydrazine-directed $\mathrm{C}-\mathrm{H}$ activation: redoxneutral and traceless by N-N bond cleavage," Angewandte Chemie International Edition, vol. 52, no. 47, pp. 1242612429, 2013.

[53] M. M. Wang, L. He, Y. M. Liu, Y. Cao, H. Y. He, and K. N. Fan, "Gold supported on mesostructured ceria as an efficient catalyst for the chemoselective hydrogenation of carbonyl compounds in neat water," Green Chemistry, vol. 13, no. 3, pp. 602-607, 2011.

[54] C. Li, Y. Chen, S. Zhang et al., "Ni-In intermetallic nanocrystals as efficient catalysts toward unsaturated aldehydes hydrogenation," Chemistry of Materials, vol. 25, no. 19, pp. 38883896, 2013.

[55] H. Lin, J. Zheng, X. Zheng, Z. Gu, Y. Yuan, and Y. Yang, "Improved chemoselective hydrogenation of crotonaldehyde 
over bimetallic AuAg/SBA-15 catalyst," Journal of Catalysis, vol. 330, no. 10, pp. 135-144, 2015.

[56] M. Zhao, K. Yuan, Y. Wang et al., "Metal-organic frameworks as selectivity regulators for hydrogenation reactions," Nature, vol. 539, no. 7627, pp. 76-80, 2016.

[57] S. Bai, L. Bu, Q. Shao, X. Zhu, and X. Huang, "Multicomponent Pt-based zigzag nanowires as selectivity controllers for selective hydrogenation reactions," Journal of the American Chemical Society, vol. 140, no. 27, pp. 8384-8387, 2018. 